\title{
Is semen polymorphonuclear leucocytes count a good predictor of male genital tract infection?
}

\author{
Lihang $\underline{C h e n}^{1}, \mathrm{MD}$, Su Ling $\underline{\mathrm{Yu}}{ }^{2}$, FRCOG, Hemashree Rajesh${ }^{2}$, MRCOG
}

INTRODUCTION This study aims to evaluate whether an increased polymorphonuclear leucocyte (PMN) count in semen is a good predictor of male genital tract infection, which is detected by semen culture.

METHODS A retrospective cross-sectional study examining the semen of 388 men was conducted at the in vitro fertilisation centre of a tertiary hospital. We compared the culture results of 109 men with increased semen PMN count against those of 279 men with normal semen PMN count.

RESULTS There was no significant difference in the percentage of positive cultures between men with increased PMN count in their semen and those without PMN count elevation (original sensitivity $20.8 \%$, specificity $70.3 \%$; $p=0.1289$ ). The overall percentage of positive semen cultures among all 388 patients was $18.6 \%$.

CONCLUSION Based on the positive cultures of significant organisms in the semen of our cohort, an increased semen PMN count is not a good predictor of genital tract infection in men.

Keywords: bacteriospermia, infertility, male genital tract infection, polymorphonuclear leucocytes, sperm analysis

\section{INTRODUCTION}

An increased polymorphonuclear leucocyte (PMN) count in semen has long been associated with male genital tract infections such as urethral, epididymis and prostate infections. The 2010 World Health Organization (WHO) laboratory manual for the examination and processing of human semen lists the threshold for normal semen analysis as less than $1.0 \times 10^{6}$ peroxidase-positive cells (i.e. PMN)/mL.(1) Leucocytospermia often indicates an inflammatory condition, and is associated with possible infection and poor sperm activity. Bezold et al(2) have concluded that bacteriospermia, especially in sexually transmitted diseases, is a likely cause of male infertility and may jeopardise the pregnancy rate for in vitro fertilisation (IVF). Therefore, the detection of bacteriospermia is of high importance. Cumming and Carrell have concluded that it is more costeffective and prudent to first perform reflexive culture for leucocytospermic patients before proceeding with IVF. ${ }^{(3)}$ However, Lackner et al has shown that an increased PMN has low sensitivity and specificity in predicting bacteria in semen.(4) One study has also demonstrated a $50 \%$ false positive rate in culture due to contamination during semen collection. ${ }^{(5)}$ Thus, although it is common practice to order semen culture when PMN is increased, leucocytospermia is a poor marker for bacteriospermia or impaired semen quality. Directly detecting bacteria in semen is not feasible since it requires a Gram stain, which is not commonly used in semen analysis, (1) and has a high false negative rate. Cross-sectional studies by Lackner et al(6) and Gdoura et $\mathrm{a}^{(7)}$ have also compared the culture positivity of the semen of patients with and without leucocytospermia. Since there has been no published studies on the Singapore population so far, we aimed to determine whether an increased
PMN count in semen is a good predictor of the presence of male genital tract infection, which is detected by semen culture.

\section{METHODS}

Between January 2005 and February 2011, we conducted a retrospective evaluation of a total of 388 men (aged 20-50 years) who had undergone semen analysis at the Centre for Assisted Reproduction (CARE) in Singapore General Hospital, Singapore. It is the practice of the hospital to order a semen culture for every man prior to IVF. Men with a sperm concentration $<5$ million/mL were excluded from the study. Of the 388 men, 109 had increased PMN count and 279 had normal PMN count.

All semen was collected by masturbation, after ejaculation of old sperm and abstinence for at least three days. Semen samples were collected under standard instructions - the penis was to be washed and dried thoroughly before the collection of semen in a sterile container. Specimens were sent to the laboratory within an hour of collection and analysed according to the 1999 WHO laboratory manual. ${ }^{(8)}$ PMN count was analysed using peroxidase staining with benzidine dye at the CARE laboratory. This test is useful for the initial screening for granulocytes, as granulocytes characteristically express the peroxidase enzyme. Well-prepared samples were mixed with a working solution before being vortexed and incubated for 20-30 minutes for staining. Counting of the cells and conversion into standard units were done using computer-aided sperm analysis. This analysis is able to easily distinguish PMN from other multinuclear components (e.g. spermatids) in the semen specimen. Measurement of sperm concentration and differentiation of spermatozoa from particulate debris were also done using computer-aided sperm analysis. The cutoff value for

${ }^{1}$ Department of Internal Medicine, John A Burns School of Medicine, University of Hawaii, Honolulu, HI, USA, ${ }^{2}$ Centre for Assisted Reproduction, Singapore General Hospital, Singapore

Correspondence: Dr Lihang Chen, Resident, Department of Internal Medicine, John A. Burns School of Medicine, University of Hawaii, 1356 Lusitana Street, Honolulu, HI 96813, USA. lihang_chen@126.com 
Table I. Semen PMN and culture results before and after adjustment for contamination.

\begin{tabular}{|c|c|c|c|c|c|c|}
\hline \multirow[t]{2}{*}{ Semen analysis } & \multicolumn{3}{|c|}{ Culture before adjustment } & \multicolumn{3}{|c|}{ Culture after adjustment } \\
\hline & Positive $^{+}$ & Negative & Total & Positive ${ }^{*}$ & Negative & Total \\
\hline Positive PMN* & 18 & 91 & 109 & 15 & 94 & 109 \\
\hline Negative PMN & 68 & 211 & 279 & 57 & 222 & 279 \\
\hline Total & 86 & 302 & 388 & 72 & 316 & 388 \\
\hline
\end{tabular}

Data is presented as number of patients. * Positive PMN is defined as $\geq 1.0 \times 10^{6} \mathrm{PMN} / \mathrm{mL}$ of semen. ${ }^{\dagger}$ Positive culture indicates detection of microorganism in patient's semen sample, values also include PCR-positive patients. " Positive culture indicates detection of pathogenic microorganism in patient's semen sample. PMN: polymorphonuclear leucocyte

PMN used in our pathology lab is $1.0 \times 10^{6} \mathrm{PMN} / \mathrm{mL}$, which is the value suggested in the 1999 WHO laboratory manual. ${ }^{(8)}$

Using freshly prepared blood agar and chocolate agar with $1 \%$ isovitalex, semen samples were cultured to detect aerobic and anaerobic bacterial species by incubation for 48 hours in $5 \% \mathrm{CO}_{2}$ in air at $37^{\circ} \mathrm{C}$. In addition to Gram-staining and microscopic inspection of the isolated colonies, the bacterial species were identified using the computerised OmniLog Combo system (Biolog Inc, California, USA) in the pathology department of Singapore General Hospital, Singapore. All the semen samples were analysed for the presence of Ureaplasma (U.) spp. (including U. urealyticum and U. parvum), Mycoplasma hominis, and Chlamydia trachomatis by polymerase chain reaction (PCR) at the pathology department. To determine the difference between groups, data were analysed by chi-square test using the Statistical Package for Social Sciences version 15.0 (SPSS Inc, Chicago, Illinois, USA). The null hypothesis in our study is that there is no difference in culture positivity between increased PMN and normal PMN groups. A p-value of $<0.05$ was considered significant.

\section{RESULTS}

Of the 388 men, 302 had negative cultures (Table I). The prevalence of genital tract infection was $18.6 \%$ among the infertile men in our cohort. Pathogenic and normal bacterial species were distinguished by the number of isolates found among different patients. 52 patients had one bacterial isolate, 22 had two isolates, 6 had three isolates, and 2 had four isolates (data not shown). However, among the patients with one or two bacterial isolates, six patients had cultures that grew known contamination species (3 alpha-haemolytic Streptococcus isolates, 2 Staphylococcus aureus isolates and 1 Staphylococcus lugdunensis isolate) and hence were considered to have normal flora. Therefore, 14 cultures (the 6 that grew known contamination species and the 8 that had more than two isolates) were regarded as false positives. The adjusted results are summarised in Table I. The most commonly detected bacteria were the Enterococcus spp. (30.6\%), followed by Escherichia coli (14.5\%) and Group B Streptococcus (12.1\%) (Table II). The PCR results for the Ureaplasma spp. (including $U$. urealyticum and U. parvum), Mycoplasma hominis and Chlamydia trachomatis are also listed in Table II.

Gdoura et al suggested that a PMN count $\geq 0.275 \times 10^{6} \mathrm{PMN} / \mathrm{mL}$ has the highest sensitivity/specificity
Table II. Bacterial culture and PCR results.

\begin{tabular}{|c|c|}
\hline Positive cultures & Count (\%) \\
\hline Enterococcus spp. & $38(30.6)$ \\
\hline Escherichia coli & $18(14.5)$ \\
\hline Group B Streptococcus & $15(12.1)$ \\
\hline Proteus mirabilis & $9(7.3)$ \\
\hline Klebsiella spp. & $8(6.5)$ \\
\hline Citrobacter koseri & $6(4.8)$ \\
\hline Morganella morganii & $5(4.0)$ \\
\hline Pseudomonas aeruginosa & $4(3.2)$ \\
\hline Acinetobacter spp. & $1(0.8)$ \\
\hline Citrobacter freundii & $1(0.8)$ \\
\hline Enterobacter spp. & $1(0.8)$ \\
\hline Proteus vulgaris & $1(0.8)$ \\
\hline $\begin{array}{l}\text { Contamination spp. } \\
\text { Alpha-haemolytic Streptococcus } \\
\text { Staphylococcus aureus } \\
\text { Staphylococcus lugdunensis }\end{array}$ & $\begin{array}{l}3(2.4) \\
2(1.6) \\
1(0.8)\end{array}$ \\
\hline $\begin{array}{l}\text { Positive PCR rates* } \\
\text { Ureaplasma spp. } \\
\text { Mycoplasma hominis } \\
\text { Chlamydia trachomatis }\end{array}$ & $\begin{array}{l}5(4.0) \\
4(3.2) \\
2(1.6)\end{array}$ \\
\hline Total & 124 \\
\hline
\end{tabular}

* Positive PCR rates indicate the presence of infection. PCR: polymerase chain reaction

Table III. Reanalysis of semen PMN and culture results using the cutoff PMN count suggested by Gdoura et al. ${ }^{(7)}$

\begin{tabular}{lccc}
\hline Semen analysis & \multicolumn{3}{c}{ No. of patients } \\
\cline { 2 - 4 } & Positive $^{+}$ & Negative & Total \\
\hline Positive PMN* & 28 & 166 & 194 \\
Negative PMN & 44 & 150 & 194 \\
Total & 72 & 316 & 388 \\
\hline
\end{tabular}

Culture results were adjusted for contamination. *Positive PMN is defined as $\geq 0.275 \times 10^{6} \mathrm{PMN} / \mathrm{mL}$ of semen. ${ }^{\dagger}$ Positive culture indicates detection of pathogenic microorganism in patient's semen sample. PMN: polymorphonuclear leucocyte

ratio for detecting bacteria. ${ }^{(7)}$ Hence, we reanalysed the groups, taking a PMN count of $\geq 0.275 \times 10^{6} \mathrm{PMN} / \mathrm{mL}$ to be positive for PMN, and a PMN count of $<0.275 \times 10^{6} \mathrm{PMN} / \mathrm{mL}$ to be negative for PMN. The results are presented in Table III. Both sensitivity $(38.9 \%)$ and specificity $(47.5 \%)$ were found to be low.

\section{DISCUSSION}

There was no statistically significant difference $(p>0.05)$ in the number of positive cultures between patients with increased PMN count and those with normal PMN count. Similar conclusions were drawn by Schaeffer et $\mathrm{al}^{(9)}$ and Berger et al. ${ }^{(10)}$ 
Rodin et $\mathrm{al}^{(11)}$ and Eggert-Kruse et $\mathrm{al}^{(12)}$ also showed that an increased PMN count had limited value in the diagnosis of semen infection. A study by Cumming and Carrell did not find any association between bacteriospermia and the severity of PMN count. ${ }^{(3)}$ Studies by Eggert-Kruse et $\mathrm{a}^{(13)}$ and Cardoso et $\mathrm{al}^{(14)}$ also found no association between increased PMN count and prostate infection, or infection in other parts of the male genital tract.

In our cohort, some patients with normal PMN levels had positive cultures. This could be due to bacteria residing in the urinary tract, which does not initiate a PMN reaction or an inflammatory response. However, increased PMN count was found in both of the patients with a chlamydial infection and in three of the five Ureaplasma-positive patients. Only one of the four patients, in whom a mycoplasma infection was detected, had an increased PMN count. These results seem to indicate that chlamydial and ureaplasma infections were associated with an increased PMN count; however, the sample size of the present study was not large enough for this finding to be conclusive.

In IVF, the detection of an increased PMN count and bacteriospermia is important because IVF procedures require a sterile environment and good quality sperms. Virecoulon et al proposed that repeated cultures, numbering more than two, of the same bacterial species suggest a male accessory gland infection that requires antibiotic treatment. ${ }^{(15)}$ It is, however, important to note that patients with increased PMN count may not necessarily have a bacterial infection; they may only have an inflammation. For example, an increased PMN count may occur due to the presence of a viral sexually transmitted infection (STI), which may cause inflammation but present with negative culture results. Additionally, Kiessling et $\mathrm{al}^{(16)}$ demonstrated that PMN may function as sperm surveillance, preventing abnormal sperms from reaching the ejaculate. Bezold et $\mathrm{al}^{(2)}$ showed a prevalence of $18.7 \%$ of viral STI in asymptomatic infertile patients, highlighting the possibility that the presence of Cytomegalovirus, herpes simplex virus or human papillomavirus type 16 affects semen quality, resulting in a low sperm count, poor motility or morphology, and altered epididymal function. Another important source of PMN in semen, according to a National Institutes of Health study by Schaeffer et $\mathrm{al}^{\left({ }^{(9)}\right.}$ is the prostate and accessory glands. This source, however, is difficult to evaluate. We feel that an increased PMN count is not an indicator for antibiotic treatment, and that anti-inflammatory agents may be effective in lowering the PMN count. Also, reactive oxygen species, proteases and cytokines resulting from an increased PMN count have been considered the mechanism of sperm damage in a study by Gdoura et al. ${ }^{(7)}$ Using a COX-2 inhibitor, Lackner et al were able to reduce leucocytospermia and increase sperm count in patients with abacterial leucocytospermia. ${ }^{(4)}$

In sexual reproduction, the female genital tract has lysozymes, phagocytes and lactic acid, which function as a natural defence mechanism against microbial infection from semen. However, since IVF procedures bypass the defence mechanism present in sexual reproduction (i.e. the embryo is transferred directly into the uterine cavity), it is crucial that semen collection is sterile and men with a positive culture are treated, in order to reduce the contamination rate of an IVF embryo. In our practice, patients with a positive semen culture undergo antibiotic treatment without further investigation. A study by Cardoso et $\mathrm{al}^{(14)}$ demonstrated that antibiotic treatment resulted in improved semen quality, in the areas of total sperm concentration, motility, viability, total motile sperm per ejaculate and PMN concentration. The antibiotic therapy in the Cardoso study ${ }^{(14)}$ consisted of trimethoprim/sulfamethoxazole, ciprofloxacin, doxycycline/minocycline, which lasted 90 days and targeted susceptible organisms.

While a positive culture does not necessarily indicate a genital tract infection, it is the only reliable method by which the presence of an infection can be demonstrated. Therefore, it is necessary to rule out false positives that arise due to the normal flora of microorganisms present in the male genital tract. Normal bacterial flora consists of the Staphylococcus spp., alpha-haemolytic Streptococcus and low titres of $U$. urealyticum. Isolation of these species was considered as contamination in our study. Mycoplasma hominis is not considered part of normal bacterial flora. Rodin et al ${ }^{(11)}$ suggested that asymptomatic multiple isolates from cultures should be considered as contaminants, and Virecoulon et $\mathrm{al}^{(15)}$ indicated that a threshold $\geq 10^{4}$, instead of $10^{3}$, colonyforming units $/ \mathrm{mL}$ is better for distinguishing infection from contamination. Additionally, Willén et $\mathrm{al}^{(17)}$ found that the bacterial flora of the coronal sulcus and distal urethra are common sources of semen contamination (71\%).

Rodin et al, in their study, found Streptococcus viridians (15.4\%) and Staphylococcus (25.4\%) to be the commonly isolated normal bacterial flora from positive semen cultures. ${ }^{(11)}$ However, the present study had a contamination rate of only $4.9 \%$, which could be attributed to strict instructions regarding hygiene at collection. Clear written and spoken instructions were given prior to sample collection, as recommended in the 2010 WHO laboratory manual. ${ }^{(1)}$ To reduce the contamination rate, the 2010 WHO laboratory manual recommends good hygiene practices before collection of the semen sample after urination, in addition to washing the penis and hands with soap and disinfectant. ${ }^{(1)}$ Virecoulon et $\mathrm{al}^{(15)}$ suggested that in order to achieve sterile semen collection, cleansing of the lower urinary tract via urination after adequate water intake is required prior to semen collection. Also, patients in the Virecoulon study applied bactericidal and antifungal soap on their penis and rinsed it off with sterilised saline to minimise contamination. This method proved effective as none of their cultures had Staphylococcus aureus as a contaminant. ${ }^{(15)}$

The prevalence of bacteriospermia in semen samples varies across different studies $-51 \%{ }^{(5)}$ in Cottell et al's study, $35.7 \%{ }^{(4)}$ 
and $51.1 \%^{(6)}$ in Lackner et al's studies, $56.9 \%{ }^{(7)}$ in Gdoura et al's study, and $63.9 \%{ }^{(11)}$ in Rodin et al's study. The prevalence of bacteriospermia in the present study was $18.6 \%$, which is much lower than those previously reported. The most common species detected differs from study to study - Chlamydia trachomatis (41.4\%) was common in Gdoura et al's study, ${ }^{(7)}$ while Staphylococcus (25.4\%) was the main culprit in Rodin's study. ${ }^{(11)}$ In the present study, Chlamydia trachomatis was detected in $1.6 \%$ of patients. Interestingly, both Eggert-Kruse et $\mathrm{al}^{(12)}$ and Willén et $\mathrm{al}^{(17)}$ observed no difference between the species isolated from semen samples of fertile and infertile couples. The effect of bacteriospermia on sperm quality and treatment requirement depends on the bacterial species isolated. Since the detection of Streptococcus viridans and Enterococcus faecalis is usually associated with urogenital tract infection, which results in low sperm parameters, Rodin et $\mathrm{al}^{(11)}$ have suggested that those infections be treated. Cardoso et $\mathrm{al}^{(14)}$ investigated other parameters such as urethral swab, urine and prostate fluid as possible methods of detecting infection in the male genital tract; their results showed the detection of mainly two species: Enterococcus faecalis (six out of 29 patients' prostate fluid tested positive) and Arcanobacterium haemolyticum (three patients tested positive). In our study, the most common isolates were Enterococcus and Escherichia coli, and five cases with Ureaplasma spp. were detected. Rodin et al ${ }^{(11)}$ showed that low titres of Ureaplasma $\left(<10^{4}\right)$ had no relationship with leucocytospermia and the quality of sperm, while Berger et $\mathrm{al}^{(10)}$ and Zheng et $\mathrm{al}^{(18)}$ showed that high titres $\left(>10^{4}\right)$ of $U$. urealyticum affects the quality and activity of sperms.

According to the 2010 WHO laboratory manual, ${ }^{(1)}$ there is controversy concerning the cutoff value of PMN for diagnosis. Whether the recommended threshold value of $1.0 \times 10^{6} \mathrm{PMN} / \mathrm{mL}$ is considered too high or too low depends on various conditions, such as semen quality, results of IVF, presence of bacteria in the semen, and sperm response to reactive oxygen species. Gdoura et al suggested that a cutoff value of $0.275 \times 10^{6} \mathrm{PMN} / \mathrm{mL}$ has a better sensitivity/specificity ratio in predicting the presence of bacteria in semen. ${ }^{(7)}$ However, this finding was not supported in our study, which found the sensitivity of the $0.275 \times 10^{6} \mathrm{PMN} / \mathrm{mL}$ cutoff value to still be low and not of diagnostic value. Reinhardt et $\mathrm{al}^{(19)}$ and Kopa et $\mathrm{al}^{(20)}$ have recommended including the determination of biochemical markers of inflammation, like granulocyte elastase or interleukin 6. Eggert-Kruse et al found no significant association between serum and semen PMN elastase with infertility, ${ }^{(13)}$ but in another study ${ }^{(12)}$ showed that the presence of albumin in semen samples might be a valuable marker for subclinical infection-inflammation of the male genital tract, making it a suitable marker in screening for infertility. Since leucocytospermia can impair sperm motility and quality, Schaeffer et $\mathrm{al}^{(9)}$ concluded that leucocytospermia is a predictor for implantation, clinical pregnancy and live birth rate in intracytoplasmic sperm injection.
In conclusion, the present study showed that an increased PMN count in semen is not a significant predictor for male semen infection, as it has unsatisfactory sensitivity and specificity.

\section{ACKNOWLEDGEMENTS}

We would like to thank Mr Christopher Lalonde (Information and Technology Support) for his help in the retrieval of clinical data for analysis. We also thank the scientists, nurses and staff of CARE, Singapore General Hospital, Singapore, who provided us with their support and help in the analysis of semen samples and education of patients.

\section{REFERENCES}

1. Cooper TG, Aitken J, Auger J, et al, eds. WHO laboratory manual for the examination and processing of human semen. 5th ed. Switzerland: World Health Organization, 2010.

2. Bezold G, Politch JA, Kiviat NB, et al. Prevalence of sexually transmissible pathogens in semen from asymptomatic male infertility patients with and without leukocytospermia. Fertil Steril 2007; 87:1087-97.

3. Cumming JA, Carrell DT. Utility of reflexive semen cultures for detecting bacterial infections in patients with infertility and leukocytospermia. Fertil Steril 2009; 91 (4 Suppl):1486-8.

4. Lackner JE, Herwig R, Schmidbauer J, et al. Correlation of leukocytospermia with clinical infection and the positive effect of antiinflammatory treatment on semen quality. Fertil Steril 2006; 86:601-5.

5. Cottell E, Harrison RF, McCaffrey M, et al. Are seminal fluid microorganisms of significance or merely contaminants? Fertil Steril 2000; 74:465-70.

6. Lackner J, Schatzl G, Horvath S, Kratzik C, Marberger M. Value of counting white blood cells (WBC) in semen samples to predict the presence of bacteria. Eur Urol 2006; 49:148-52; discussion 152-3.

7. Gdoura R, Kchaou W, Znazen A, et al. Screening for bacterial pathogens in semen samples from infertile men with and without leukocytospermia. Andrologia 2008; 40:209-18.

8. Aitken RJ, Baker HW, Barratt CL, et al, eds. WHO laboratory manual for the examination of human semen and sperm-cervical mucus interaction. 4th ed. Cambridge, United Kingdom: World Health Organization, 1999.

9. Schaeffer AJ, Knauss JS, Landis JR, et al. Leukocyte and bacterial counts do not correlate with severity of symptoms in men with chronic prostatitis: the National Institutes of Health Chronic Prostatitis Cohort Study. J Urol 2002; 168:1048-53.

10. Berger RE, Karp LE, Williamson RA, et al. The relationship of pyospermia and seminal fluid bacteriology to sperm function as reflected in the sperm penetration assay. Fertil Steril 1982; 37:557-64.

11. Rodin DM, Larone D, Goldstein M. Relationship between semen cultures, leukospermia, and semen analysis in men undergoing fertility evaluation. Fertil Steril 2003; 79 Suppl 3:1555-8.

12. Eggert-Kruse W, Probst S, Rohr G, Aufenanger J, Runnebaum B. Screening for subclinical inflammation in ejaculates. Fertil Steril 1995; 64:1012-22.

13. Eggert-Kruse W, Zimmermann K, Geissler W, et al. Clinical relevance of polymorphonuclear (PMN-) elastase determination in semen and serum during infertility investigation. Int J Androl 2009; 32:317-29.

14. Cardoso EM, Santoianni JE, De Paulis AN, et al. Improvement of semen quality in infected asymptomatic infertile male after bacteriological cure. Medicina (B Aires) 1998; 58:160-4.

15. Virecoulon F, Wallet F, Fruchart-Flamenbaum A, et al. Bacterial flora of the low male genital tract in patients consulting for infertility. Andrologia 2005; 37:160-5.

16. Kiessling AA, Lamparelli N, Yin HZ, Seibel MM, Eyre RC. Semen leukocytes: friends or foes? Fertil Steril 1995; 64:196-8.

17. Willén M, Holst E, Myhre EB, Olsson AM. The bacterial flora of the genitourinary tract in healthy fertile men. Scand J Urol Nephrol 1996; 30:387-93.

18. Zheng J, Yu SY, Jia DS, et al. [Ureaplasma urealyticum infection in the genital tract reduces seminal quality in infertile men]. Zhonghua Nan Ke Xue 2008; 14:507-12. Chinese.

19. Reinhardt A, Haidl G, Schill WB. Granulocyte elastase indicates silent male genital tract inflammation and appropriate anti-inflammatory treatment. Andrologia 1997; 29:187-92.

20. Kopa Z, Wenzel J, Papp GK, Haidl G. Role of granulocyte elastase and interleukin- 6 in the diagnosis of male genital tract inflammation. Andrologia 2005; 37:188-94. 